\title{
Gelen Akım Arası Kısa Süreli Zaman Aralığını Modelleyebilmek Amacıyla Poisson Dağılım Fonksiyonu Modifikasyonu
}

\section{Poisson Distribution Function Modification to Model Short Time Intervals of Arrival Flow}

\begin{abstract}
Ekinhan Erişkin ${ }^{1 *}$
Geliş / Received: 23/02/2021

Revize / Revised: 13/04/2021

Kabul / Accepted: 29/04/2021

\section{$\overline{\mathbf{O Z Z}}$}

Poisson dağılımı genel olarak kullanılan bir olasılık yoğunluk fonksiyonudur. Bu dağılım trafik akımının modellenebilmesi amaciyla da kullanılmaktadır. Fakat faktöriyel hesab1 ile elde edilmesi sebebiyle süreksiz olasılık ailesine ait olan bu dağılımın, 1'den küçük ve katlarının hesabında kullanılması mümkün değildir. Bu çalışmada faktöriyel hesabı yerine $\mathrm{n}$ ! değerinin $\Gamma(\mathrm{n}+1)$ eşitliğinden yararlanılarak gamma fonksiyonu kullanılmıştır. Yapılan bu dönüşüm ile süreksiz olasılık ailesine ait olan dağılım sürekli forma dönüştürülmüştür. Dönüşüm sonrası Isparta ili caddesi üzerinden akşam zirve saat dilimi sürecinde geçen akım, taşıtlar arası zaman cinsinden boşluk değerlerine göre modellenmiştir. Yapılan modelleme sonrası kısa süreli boşluk modellemelerinde gamma fonksiyonu ile dönüştürülen poisson olasılık fonksiyonu başarılı sonuç vermiştir. Ayrıca tam sayı değerlerde de her iki fonksiyonunda aynı değeri verdiği görülmüştür. Sonuç olarak modifiye edilmiş fonksiyonun kullanılabilirliği ortaya konmuştur.
\end{abstract}

Anahtar Kelimeler- Poisson Dağılımı, Gamma Fonksiyonu, Trafik Akımı, Benzetim

\begin{abstract}
The Poisson distribution is a commonly used probability density function. This distribution is also used to model the traffic flow. However, since it is obtained by factorial calculation, it is not possible to use this distribution, which belongs to the discontinuous probability family. In this study, instead of factorial calculation, the gamma function is used by making use of the $n$ ! equality to $(n+1)$. Hence, the distribution belonging to the discontinuous probability family was transformed into continuous form. After the transformation, flow of a street in Isparta city street during the evening peak time was modeled according to the time gap values between vehicles. After the modeling, the Poisson probability transformed by gamma function yielded successful results in short-term gap modeling. In addition, it was seen that both functions gave the same value in integer values. As a result, the usability of the modified function was revealed.
\end{abstract}

Keywords- Poisson Distribution, Gamma Function, Traffic Flow, Simulation

1*Sorumlu yazar iletișim: ekinhaneriskin@sdu.edu.tr (https://orcid.org/0000-0002-0087-0933)

Mülkiyet Koruma ve Güvenlik Bölümü, Süleyman Demirel Üniversitesi, Isparta, Türkiye 


\section{GİRIŞ}

Ulaşım ağının tasarlanmasında trafik akımı önemli bir parametredir. Özellikle de birçok yolun başka birçok yol ile kesişmesi sonucunda çok sayıda kavşakların oluşması sağlanan şehir içi ulaşım ağı için. Bu kesişmeler sebebiyle kavşaklar şehir içi ulaşım ağının kritik geometrik parçalarındandır. Eğer bu kritik noktalar üzerinde herhangi bir kontrol mekanizması uygulanmaz ise kavşağa bağlanan kolların çıkış, birleşme ve kesişme yaşadığı noktalarda kritik noktalar oluşmaktadır. 3 kollu bir kavşak için bu kritik noktalarının sayısı denetimsiz bir kavşak için 9 iken bu sayı 4 ve 5 kollu denetimsiz kavşaklar için 32 ve 79'a kadar çıabilmektedir [1]. Bu değerlerden de anlaşılacağ 1 gibi, denetimsiz kavşaklarda kritik nokta sayısı kavşak kolunun kuvveti olarak artmaktadır. Denetimsiz kavşağın kol sayısındaki artış, oluşan kritik nokta sayısında da artışa neden olmaktadır.

Hakkert ve Mahalel [2], çalışmalarında kavşakların ne kadar kritik öneme sahip olduklarını göstermişlerdir. Yaptıkları çalışma ile ABD'de gerçekleșen kazaların istatistiksel analizi gerçekleştirmişlerdir. Gerçekleştirilen analiz neticesinde kayıtlara geçen kazaların \%50'sinin kavşaklarda meydana geldiğini göstererek kavşakların önemini ortaya koymuşlardır. Gelişen teknolojiye rağmen, 40 yıl sonra Karayolları Genel Müdürlüğü (KGM) [3] tarafindan yayınlanan istatistikler, kavşakların hala daha önemini sürdürdüğünü göstermektedir. KGM tarafından gerçekleştirilen istatistiksel analiz kapsamında, Türkiye içerisinde kayıtlara geçen trafik kazalarının \%37.7'lik kısmının kavşaklarda meydana geldiği ifade edilmektedir. Bu nedenle, son yıllarda yaşanan teknolojik gelişmelere rağmen kavşaklardaki güvenlik sorunları hala daha devam etmektedir.

Kavşaklarda var olan güvenlik sorunlarının çözülmesi doğru tasarlanmış denetim mekanizmaları ile gerçekleştirilebilir. Trafik sinyalizasyon sistemleri denetim için doğru bir yöntem olarak kabul edilebilir eğer doğru tasarlanmış olursa. Trafik sinyalizasyon sistemlerinin avantajı, kavşak kollarına geçiş üstünlüğünü net bir şekilde vermesidir. Fakat, sinyalizasyon sisteminin doğru ve optimum olarak tasarlanmamış olması durumunda kavşaklarda gecikme ve gereksiz kuyruk gibi sorunlar ortaya çıkmakta, sürücülerin sinyalizasyona karşı olan güveni sarsılmaktadır. Bu durum neticesinde de sürücülerin sinyalizasyon sistemlerine karşı olan dikkati azalmakta, kırmızı 1şık ihlali ile kazaya karışma riskinin arttığı düşünülmektedir. Bu problemlerin önüne geçebilmek adına trafik sinyalizasyon süreleri doğru ve optimum olarak belirlenmelidir. Fakat sinyalizasyon ile denetlenen kavşak polinom olmayan bir problemi ortaya çıkarmaktadır. Ortaya çıkan problemin polinom olmayan problem olması sebebiyle de global optimum çözümün bulunması oldukça zorlaşmaktadır [4]. Optimum sinyalizasyon tasarımının gerçekleştirilebilmesi için öncelikli olarak mevcut trafik akımının doğru ve gerçeğe uygun olarak tahmin edilmesi gerekmektedir. Bu noktada trafik akımının tahmini için istatistiksel yöntemler [5-8] kullanılmaktadır.

\section{A. Problemin Tanımı}

Trafik akımının sürekli olması ve bazı istatistiksel dağılımların süreksiz olması sebebiyle gerçeğe uygun veri modellemeleri yapılamamaktadır. Süreksiz dağılımlardan birisi de Poisson dağılımıdır. Fakat literatür çalışmalarında trafik akımının modellenmesi amacıyla poisson dağılımının kullanımı mevcuttur [9].Genel olarak geniş zaman aralıklarında poisson dağılımı trafik akımını modelleyebilmek amacıyla kullanılabilse de dinamik bir sinyalizasyon sistemi oluşturulması gerektiğinde daha kısa aralıklarda modellemeye ihtiyaç duyulmaktadır. Kavşağa yaklaşan akım içerisinde bulunan taşıtlar arası zaman cinsinden boşluk değerleri yoğun trafik durumunda kısa kalmaktadır. Taşıtlar arası kısa zaman dilimlerinde sadece tam sayı değerleri ile analiz gerçekleştirildiğinde girdi parametre verisi yetersiz kalacak, sonuçlar yeterli seviyede hassasiyete sahip olmayacaktır. Burada 1 saniyeden daha kısa taşıtlar arası zaman cinsinden boşluk değerlerinin poisson dağılımı ile hesaplanamaması çalışmanın problemini oluşturmaktadır.

\section{B. Çalışmanın Amacı ve Kapsamı}

Yukarıda belirtilen probleme çözüm üretmek için yaygın olarak kullanılan poisson dağı̆lımının $[10,11]$ daha yaygın olarak kullanılabilmesi çalışmanın amacıdır. Sadece tam sayı değerler yerine Reel sayılarda da analiz yapabilmesi amacıyla poisson dağılımı modifiye edilerek sürekli forma dönüştürülmüş ve gerçek akım için taşıtlar arası kısa süreli zaman aralığının, bu çalışma için 0-1 sn aralığı, modellenebilmesi amacıyla kullanılmıştır. Bu amacı karşılayabilmek için poisson dağılımının paydasında bulunan faktöriyel denklemi gamma eşitliği kullanılarak dönüştürülmüştür. Çalışmanın bundan sonraki kısımlarında sırasıyla poisson dağılımı, faktöriyel ile gamma fonksiyonlarının eşitliği, örnek bir saha uygulaması ve elde edilen sonuçlar sunulmuş̧tur. 


\begin{tabular}{|c|c|c|}
\hline & $\begin{array}{l}\text { BŞEÜ Fen Bilimleri Dergisi } \\
8(1), 292-299,2021\end{array}$ & $\begin{array}{r}\text { BSEU Journal of Science } \\
\text { https://doi.org/10.35193/bseufbd.885635 }\end{array}$ \\
\hline & & :2458-7575 (https://dergipark.org.tr/tr/pub/bseufbd) \\
\hline
\end{tabular}

\section{POISSON DAĞILIMI}

Poisson dağılımı bir veri setinin rastsallığını ölçen, deneysel verilerin teorik eğriye uydurulmasını sağlayan ve temel verilerden belirli tahminlerin yapılmasında kullanılan matematiksel bir bağıntıdır. Trafik mühendisliği alanında ise belirli bir noktaya ulaşma oranlarının analizi, taşı boşluklarının incelenmesi, park alanının tespit edilmesi, kazaların analizi ve sola dönüş ceplerinin tasarımı amacıyla da kullanılabilmektedir [12]. Poisson olasılık dağılım fonksiyonu (ODF) ve poisson kümülatif dağılım fonksiyonu (KDF) sirasıyla Denklem (1) ve (2)'de gösterilmiştir. Poisson dağılımı için farklı $\lambda$ değerleri ile çizilmiş örnek ODF ve KDF grafikleri Şekil 1 'de gösterilmektedir.

$$
\begin{aligned}
& O D F=\frac{\lambda^{n} e^{-\lambda}}{n !} \\
& K D F=e^{-\lambda} \sum_{i=0}^{n} \frac{\lambda^{i}}{i !}
\end{aligned}
$$

Burada $\mathrm{n}$ veri sayısını, $\lambda \mathrm{n}$ adet verinin aritmetik ortalamasını ve e ise Euler sayısını (doğal logaritmik taban değeri) ifade etmektedir.

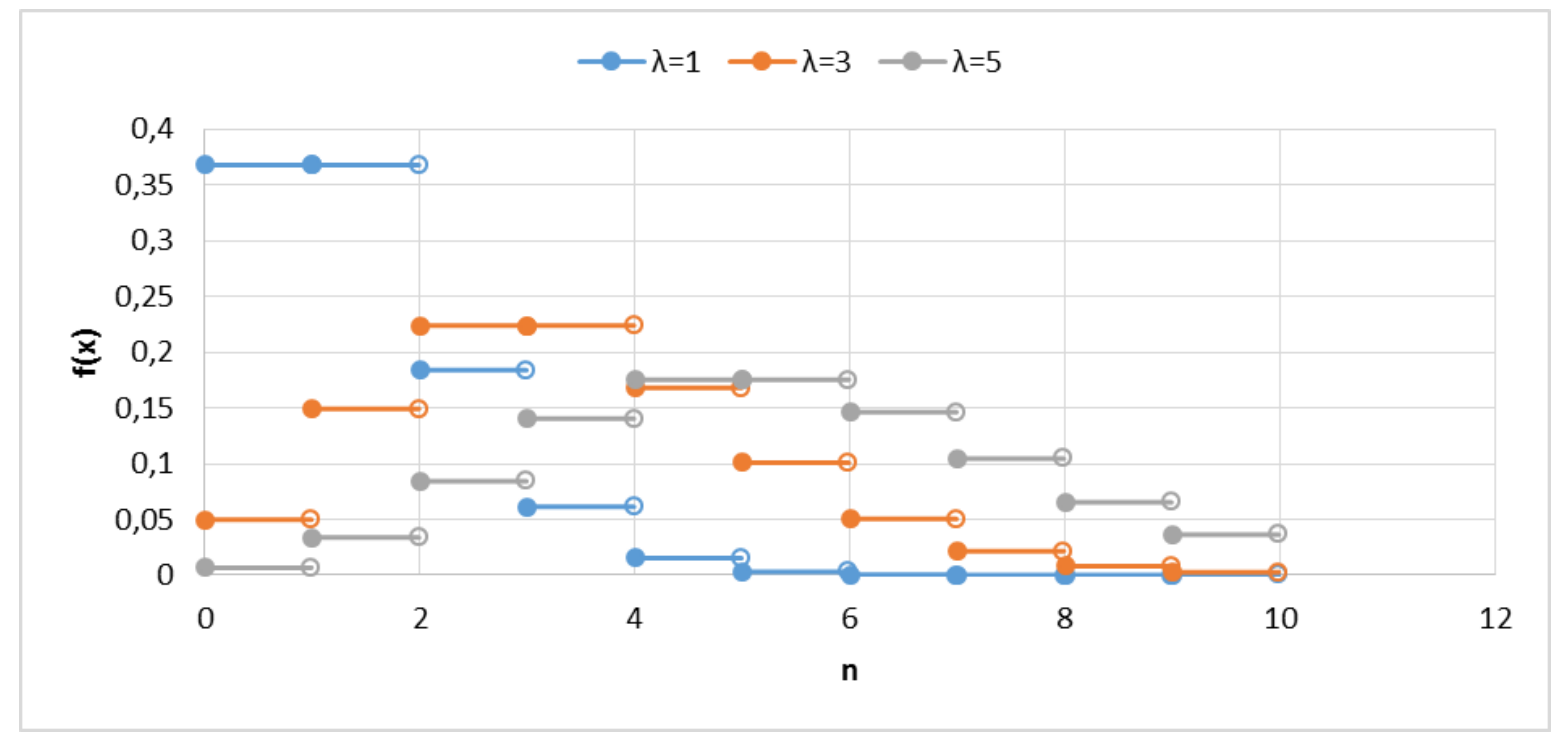

(a)

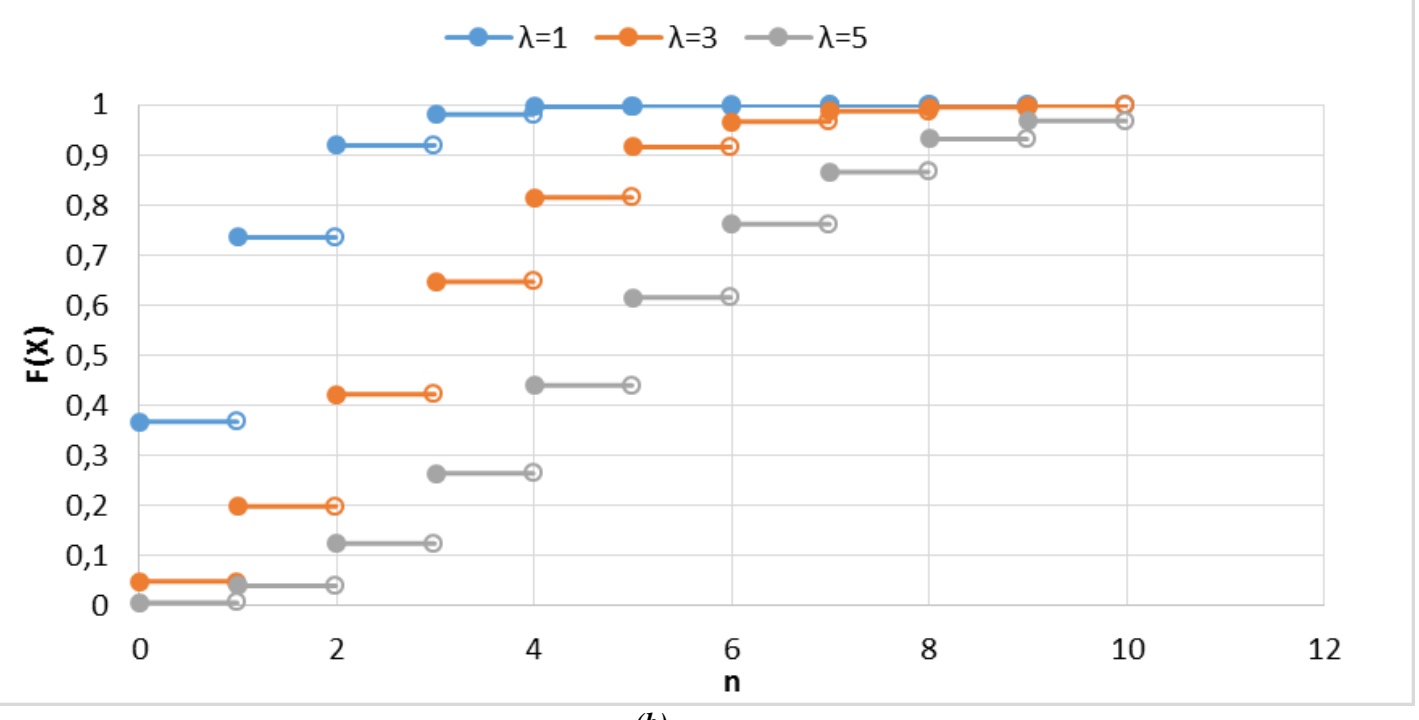

(b)

Şekil 1. Poisson dağılımı olasılık dağılım grafiği (a) ve kümülatif dağılım grafiği (b) 
Şekil 1'den de görülebileceği gibi, poisson dağılımı normal şartlar altında süreksiz bir dağılım olup faktöriyel hesabı sebebiyle sadece tam sayı değerlerine bağlı olarak hesap yapabilmektedir. Bu nedenle poisson dağılımı tam sayı analizlerinde kullanılabilmekte, fakat ondalıklı analizlerde kullanılamamaktadır. Trafik akımı gibi sürekli değişken yapıda bulunan bir durumu simule edebilmek için 1 saniyeden kısa aralıklarında istatistiksel olarak analiz edilebilmesi gereklidir. Bu çalışmada yapılacak modifikasyon ile 1 saniyeden de kısa aralıklı taşıt geliş aralıkları poisson dağılımı ile modellenebilmiştir.

\section{POISSON DAĞILIMININ MODIFIIKASYONU}

Poisson dağılımının hesabı yapılırken Denklem(1)'de, $\mathrm{n}$ ! değerinin $\Gamma(\mathrm{n}+1)$ eşitliğinden [13] yararlanılarak tekrar düzenlenmiştir. Poisson dağılımı süreksiz bir dağılımdır ve faktöriyel hesabı ile sadece tam sayıların olasılığı hesaplanabilir. Fakat bazı durumlarda ondalıklı sayıların da olasılıklarının modellenmesine ihtiyaç duyulmaktadır. Fakat tam sayı dışında analiz edilmesi istenen ondalıklı değerler için Denklem (1) mevcut hali ile kullanılamaz. Dağılımın süreklilik kazanması ve reel sayılarda da hesap yapabilmesi için faktöriyel hesabı gamma fonksiyonu (Denklem 3) yardımı ile tekrar düzenlenir ve Denklem (4) elde edilir.

$$
\begin{aligned}
& \Gamma(\mathrm{n})=\int_{0}^{\infty} \mathrm{x}^{\mathrm{n}-1} \mathrm{e}^{-\mathrm{x}} \mathrm{dx} \\
& \text { ODF }=\frac{\lambda^{\mathrm{n}} \mathrm{e}^{-\lambda}}{\int_{0}^{\infty} \mathrm{x}^{\mathrm{n}} \mathrm{e}^{-\mathrm{x} x}}
\end{aligned}
$$

Çalışmanın buradan sonraki kısımlarında poisson dağılımı hesabı için Denklem (1) yerine Denklem (4) kullanılmıştır. Denklem (1) ve (4) ile çizilen dağılım grafiği Şekil 2 ile gösterilmektedir.

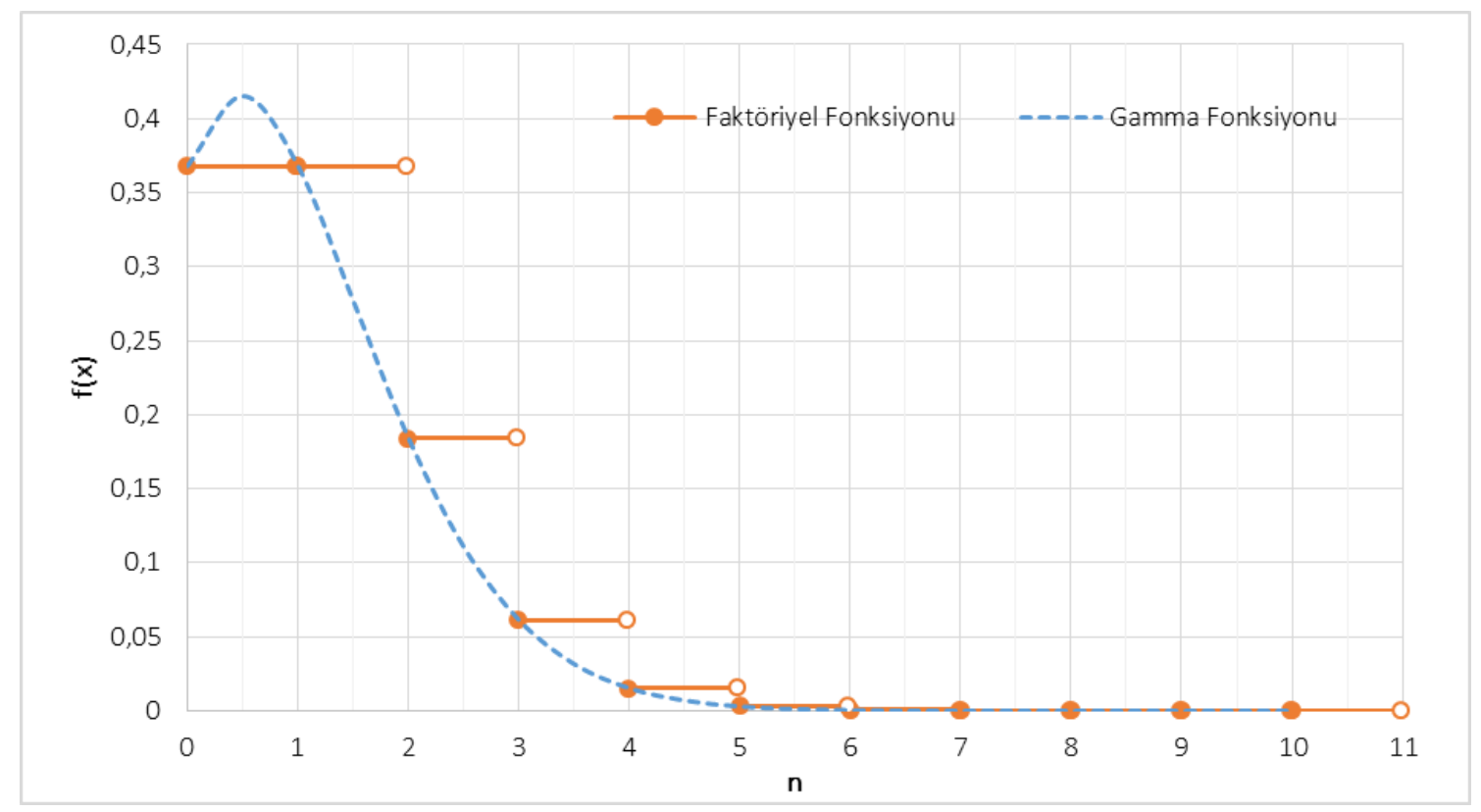

Şekil 2. Poisson dağılım fonksiyonunun gamma (Denklem 4) ve faktöriyel (Denklem 1) fonksiyonları ile oluşturulması arasındaki fark

\section{DAĞILIM FONKSIYYONLARININ KARŞILAŞTIRILMASI}

Yaygın olarak kullanılan poisson dağılımının süreksiz dağılım ailesinde olması nedeniyle sadece tam sayılar üzerinden olasılık hesabı yapabilmektedir. Bu durum trafik akımı gibi sürekli ve değişken yapılar için uygun değildir. Fakat süreksiz fonksiyon olan poisson dağılımının gamma fonksiyonu yardımı ile sürekli bir forma dönüştürülmesi ile trafik akımının analizi amacıyla da poisson dağılımı kullanılabilir olmaktadır. Bu çalışma kapsamında Isparta ili Hasan Fehmi Caddesi (Şekil 3) üzerinden poisson dağılımının sürekli ve süreksiz formunu kıyaslayabilmek amacıyla hafta içi zirve saat dilimi (17:00 - 18:00) içerisinde geçen taşıtlar arasında zaman cinsinden boşluklar analiz edilmiştir.

Analiz kapsamında öncelikle geçen taşıtlar arası zaman bir kronometre kullanarak kayıt altına alınmıştır. Elde edilen verilerin olasılık dağılımları Şekil 4'te gösterilmiştir. Kaydedilen zaman cinsinden boşlukların 


\begin{tabular}{|c|c|c|}
\hline & $\begin{array}{l}\text { BŞEÜ Fen Bilimleri Dergisi } \\
8(1), 292-299,2021\end{array}$ & $\begin{array}{r}\text { BSEU Journal of Science } \\
\text { https://doi.org/10.35193/bseufbd } 885635\end{array}$ \\
\hline $\begin{array}{l}\text { BILECIKSEYY EDEBALI } \\
\text { ONIVERSITES }\end{array}$ & & 2458-7575 (https://dergipark.org.tr/tr/pub/bseufbd) \\
\hline
\end{tabular}

istatistiksel analizi gerçekleştirilerek (Tablo 1) poisson dağılımı için ihtiyaç duyulan ortalama verisi hesaplanmıştır. Ortalama verisine bağlı olarak faktöriyel (Denklem 1) ve gamma fonksiyonu (Denklem 4) ile poisson dağılımları hesaplanmıştır. Yapılan hesaplamaların karşılaştırılması Şekil 5'te gösterilmiştir.

Tablo 1. Zaman cinsinden boșluk değerlerinin istatistiksel analizi

\begin{tabular}{cc}
\hline Parametre & Değer \\
\hline Elemansayıs1 & 1323 \\
Mod & 2.18 \\
Medyan & 3.5 \\
AritmetikOrtalama & 5.42 \\
StandartSapma & 5.46 \\
$(\sigma)$ & \\
Varyans & 29.82 \\
$\left(\sigma^{2}\right)$ & \\
Enküçükdeğer & 0.34 \\
$(s)$ & \\
Enbüyükdeğer & 56.45 \\
$(s)$ & \\
\hline
\end{tabular}

Şekil 5 incelendiğinde faktöriyel ile gamma fonksiyonu yardımıyla hesaplanan poisson dağılımlarının tam değer dışında farklılık gösterdiği anlaşılmaktadır. Her iki tahmin yöntemi ile elde edilen değerler arasındaki yüzdelik fark hesaplandığında Şekil 6 elde edilmektedir.

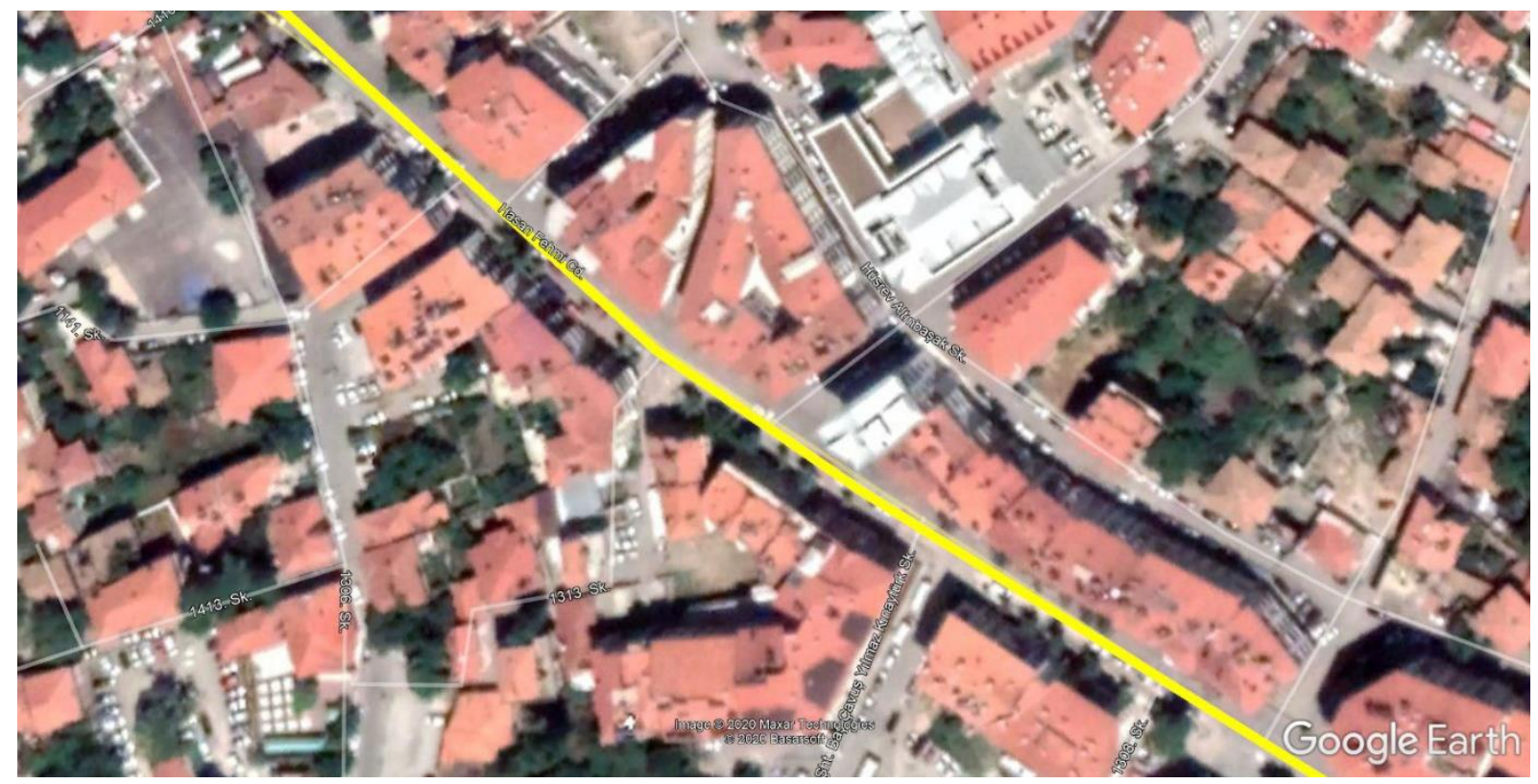

Şekil 3. Analiz edilen yol kesiminin uydu görüntüsü (Harita verisi: Google, Maxar Teknoloji, Basarsoft - 09.07.2020) 


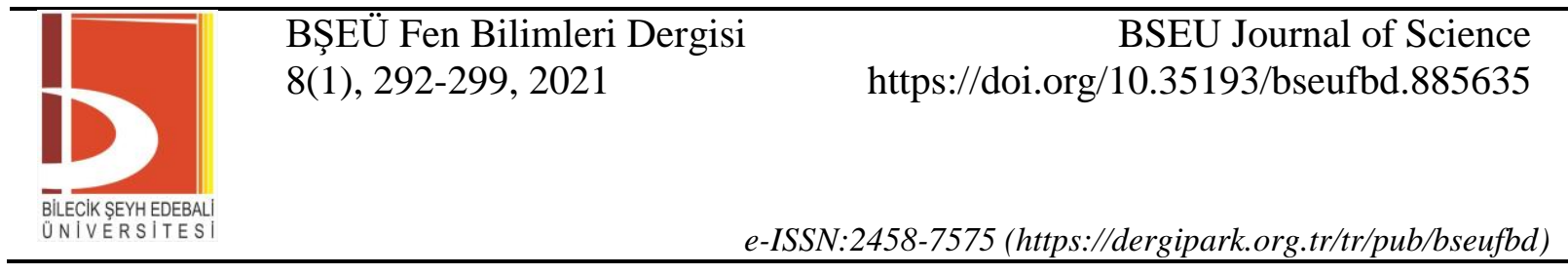

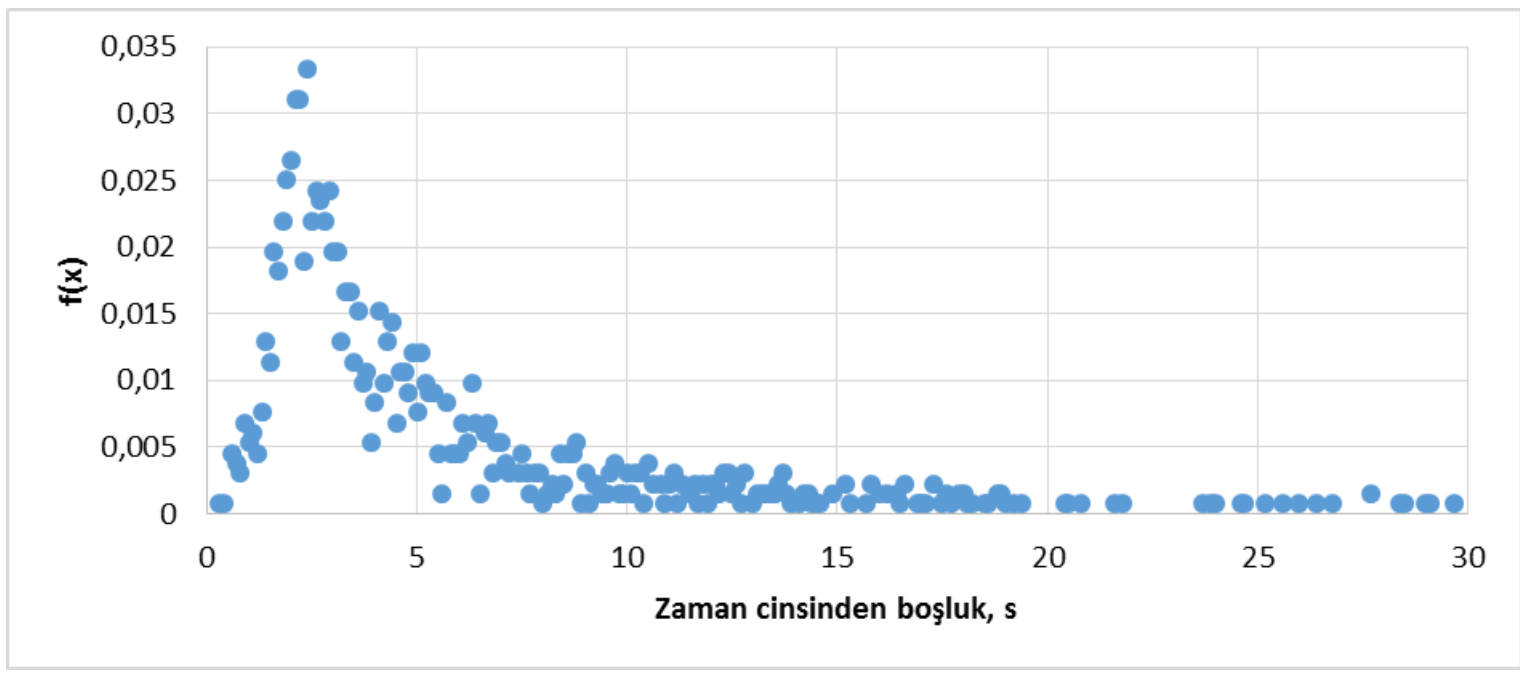

Şekil 4. Geçen taşıtların zaman cinsinden boşluklarının olasılık dağılımı

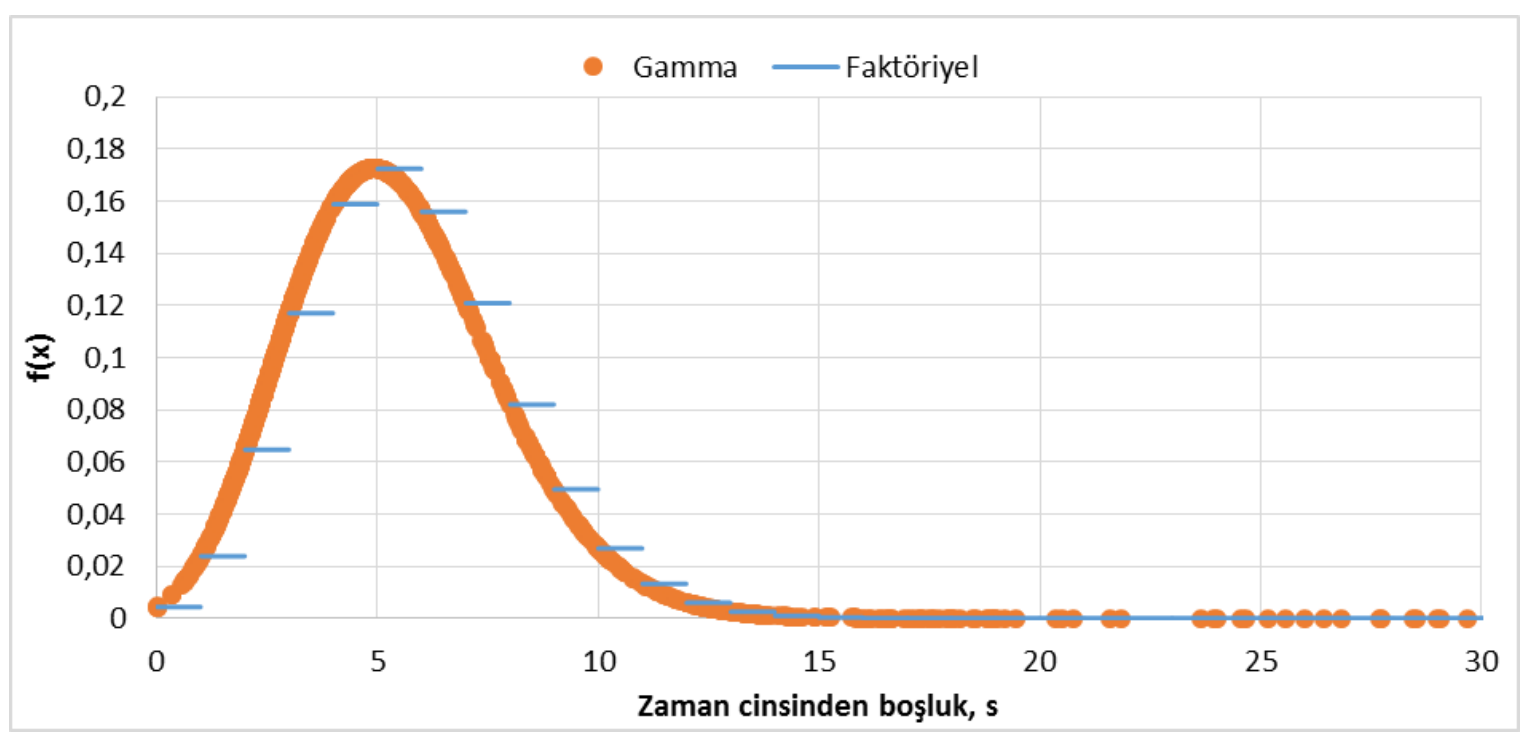

Şekil 5. Faktöriyel ve gamma fonksiyonu ile hesaplanmış poisson olasılık değerleri

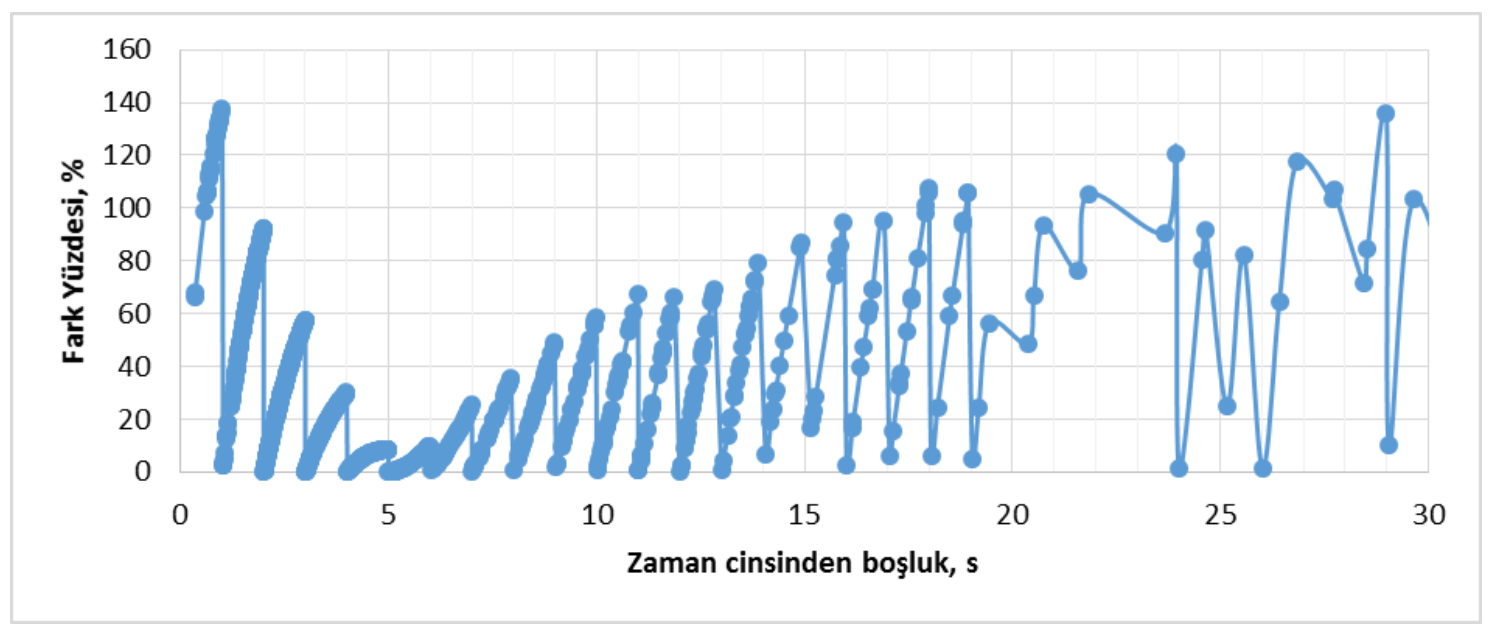

Şekil 6. Faktöriyel ve gamma fonksiyonları ile hesaplanan olasılık değerleri arasındaki fark yüzdesi 
Şekil 6 incelendiğinde tam sayılarda farkın hiç oluşmadığı görülmektedir. Burada her iki fonksiyon ile aynı değer elde edildiği için fark oluşmaması beklenen bir sonuçtur. Ayrıca zaman cinsinden boşluk değerleri arttıkça oluşan hata yüzdesi de artmaktadır. Bu sonuçta Şekil 5 incelendiğinde beklenen bir sonuçtur. Burada dikkat edilmesi gereken, Şekil 6'da gösterilen fark yüzdesinin yüzdelik değişim olmadığıdır. Burada iki sayı arasındaki yüzdelik fark hesaplanmıştır. Şekil 6 ile faktöriyel ile gamma değerleri arasında çok ciddi bir farkın oluşabildiği gözlemlenmektedir ve bu nedenle tam sayı dışında değerler ile analiz yapılmak istendiğinde sonuçlar olduğundan farklı çıkmaktadırlar.

\section{SONUC}

Bu çalışma ile kısa zaman cinsinden boşluk değerlerine sahip trafik akımının modellenebilmesi amacıyla faktöriyel hesabı ile çözümlenen poisson dağılımı gamma fonksiyonu ile modifiye edilmiştir. Bu modifikasyonda $\mathrm{n}$ ! değerinin $\Gamma(\mathrm{n}+1)$ eşitliğinden yararlanılmıştır. Bu eşitlik ile gerçekleştirilen dönüşüm sayesinde, süreksiz olasılık ailesinden olan poisson olasılık dağılımı sürekli bir dağılım haline dönüştürülmüştür. Bu dönüşüm sonucunda kısa zaman cinsinden boşluk değerlerinin de - 0 ile 1 saniye aralığı - poisson olasılık fonksiyonu yardımıyla hesaplanabilmesi mümkün olmaktadır.

Elde edilen yeni poisson dağılımı ile Isparta ilinde dikkate alınmış bir cadde üzerinde hareket eden 1324 taşıt arasındaki zaman cinsinden boşluk değerleri istatistiksel olarak analiz edilmiş hem faktöriyel hesabı yardımıyla hem de gamma fonksiyonu dönüşümü ile poisson olasılıkları hesaplanmıştır. Yapılan çalışma sonucunda poisson dağılımının gamma fonksiyonu dönüşümü ile kullanılabilir olduğu ve sürekli olarak olasılık dağılımının yapılabildiği anlaşılmıştır. Faktöriyel hesabı ile elde edilen olasılık değerleri ile gamma dönüşümü ile elde edilen olasılık değerleri arasındaki değerlerler arası fark \%140'a kadar artabilmektedir.

Poisson dağılımı ile yapılmış çalışmalar incelendiğinde; Martolos ve Andel [14] çalışmalarında geleneksel poisson dağılımı kullanmış olup düşük trafik hacmine sahip yol kesiminde 1-25 sn arasını analiz etmişlerdir. Fakat çalışmaları içerisinde 2000 tş/st trafik hacmine sahip bir yol kesiminde oluşan taşıtlar arası zaman cinsinden boşluğun \%90'dan fazlasının en fazla 5 saniye olduğunu göstermişlerdir. Gamma fonksiyonu ile modifiye edilmiş dağılım fonksiyonu ile daha kısa aralıkları analiz etmeleri mümkün olabilecektir ve bu şekilde trafik hacmi çok daha büyük yol kesimlerinin analizi mümkün olabilecektir. Martolos ve Andel [14] çalışmasına benzer olarak Vadhwani ve Thakor [15] çalışmalarında düşük trafik hacmine sahip bir yol kesimi dikkate almışlar ve kullanmışlardır. Her ne kadar gerçek saha verileri bir dakikadan daha kısa olarak elde edilmişse de geleneksel poisson dağılımı ile tam sayı değerlerin analizine odaklanılmışıı. Burada da yine gamma fonksiyonu ile modifiye edilmiş poisson dağılımı ile daha yüksek trafik hacmine sahip yol kesimlerinde analiz yapılması mümkün olacaktır.

Gelecek çalışmalar için gamma fonksiyonu ile sürekli forma dönüştürülmüş poisson olasıllk fonksiyonunun sadece bir cadde üzerinden geçen akımın modellenmesi yerine kavşaktan geçen akımların modellenerek sinyalizasyon tasarımı üzerinde çalışmalara yoğunlaşabilir. Özellikle büyük veri çağında olmamız göz önünde bulundurulduğunda [16], anlık ve hızlı olarak gerçek akımların düzgün modellenmesi amacıyla kullanılabilecek her türlü dağılım arasına poisson dağılımı da sürekli forma dönüştürülerek dahil edilebilir.

\section{KAYNAKLAR}

[1] Özinal, Y. \& Volkan, U.Z. (2021). Dönel Kavşak Geometrik Elemanlarının Kavşak Güvenliği Üzerine Etkisinin Literatür Işı̆̆ında Değerlendirilmesi. Politeknik Dergisi. 24, 1, 283-297.

[2] Hakkert, S. \& Mahalel, D. (1978). Estimating the number of accidents at intersections from a knowledge of the traffic flows on the approaches. Accident Analysis \& Prevention, 10, 1, 69-79.

[3] Karayolları Genel Müdürlüğü, (2020). Trafik kazaları özeti. kgm.gov.tr, https://www.kgm.gov.tr/SiteCollectionDocuments/KGMdocuments/Trafik/TrafikKazalariOzeti2017.pdf (Erişim tarihi: 3 Kasım 2020)

[4] Tektaş, M., Akbaş A. \& Topuz, V. (2002). Yapay Zeka Teknikleri'nin Trafik Kontrolü'nde Kullanılması Üzerine Bir İnceleme. Uluslararası Trafik ve Yol Güvenliği Kongresi, Ankara, Türkiye.

[5] Atalay A. \& Kısaoğlu, S. (2020). Farklı Kotlu Kollara Sahip Hemzemin Dönel Kavşaklardaki Kazaların Analizi: Atatürk Üniversitesi Kavşağı Örneği. Iğdır Üniversitesi Fen Bilimleri Enstitüsü Dergisi, 10, 2, 1079 1092.

[6] Alan, A. R. (2020). Impact of traffic incident duration and road characteristics on traffic flow performance. Yüksek Lisans Tezi, İnşaat Mühendisliği, Fen Bilimleri Enstitüsü, Işık Üniversitesi, İstanbul, Türkiye. 
[7] Fedotkin, M., Fedotkin, A. \& Kudryavtsev, E. (2020). Dynamic Models of Heterogeneous Traffic Flow on Highways. Autom Remote Control, 81, 1486-1498.

[8] Mamat, A. \& Chen, P. (2020). Characteristics of Arterial Travel Time Distributions with Mixed Traffic of Human-Driven and Connected and Autonomous Vehicles. 20 ${ }^{\text {th }}$ COTA International Conference of Transportation Professionals, Xi'an, China, 866-878.

[9] Oyala, C. O. \& Otumba, E. O. (2018). Modelling of distribution of the "Matatu" traffic flow using Poisson distribution in a highway in Kenya. International Mathematical Forum, 13(8), 385-392.

[10] Wang, X. B., Yin, K., \& Liu, H. (2018). Vehicle actuated signal performance under general traffic at an isolated intersection. Transportation research part C: emerging technologies, 95, 582-598.

[11] Sala, M. \& Soriguera, F. (2020). Macroscopic modeling of connected autonomous vehicle platoons under mixed traffic conditions. Transportation Research Procedia, 47, 163-170.

[12] Gerlough, D. L. \& Schuhl, A. (1955) Use of Poisson Distribution in Highway Traffic - The Probability Theory Applied to Distribution of Vehicles on Two-Lane Highways, Saugatuck, Connecticut, USA: The ENO Foundation for Highway Traffic Control. 1-58.

[13] Hyde, S. K. (2020). Properties of the Gamma function, www.byuh.edu, https://jekyll.math.byuh.edu/courses/m321/handouts/gammaproperties.pdf(Erişim tarihi: 4 Aralık 2020)

[14] Martolos, J. \& Andel, P. (2013). Distances between Vehicles in traffic Flow and the Probability of Collision with Animals. Transactions on Transport Sciences. 6(2), 97.

[15] Vadhwani, D. \& Thakor, D. (2021). Statistical analysis of vehicle detection in the ITS application for monitoring the traffic and road accident using internet of things. In Advances in VLSI and Embedded Systems, 55-70.

[16] Terzi, S. \& Erten, K. M. (2020). The effect of big data analysis for sustainable transportation. Journal of Innovative Transportation. 1, 1. 